\title{
Conflitos de uso e ameaças a paisagem da Unidade de Conservação Parque Estadual do Poeta e Repentista Juvenal de Oliveira, Campina Grande - PB: uma proposta de intervenção.
}

\author{
Conflicts of use and threats in the landscape of the Poeta e Repentista Juvenal de Oliveira's \\ Conservation Unity park state, Campina Grande - PB: an intervention proposal
}

SOUZA $^{1}$, A. S.; LIMA ${ }^{2}$, V. R. P. alexsandrouepb@gmail.com;

\begin{abstract}
Resumo
Este artigo refere-se a um estudo realizado em uma Unidade de Conservação (UC) de proteção integral, buscando oferecer direcionamentos de planejamento com base no estudo da valoração da paisagem. A UC Parque Estadual do Poeta e Repentista Juvenal de Oliveira, localizada no município de Campina Grande - PB, não possui plano de manejo e carece de pesquisas científicas que justifiquem a sua implementação, pois se trata de uma UC não regulamentada e que sofre imposições de outras territorialidades. Assim, o objetivo geral foi identificar e analisar os principais conflitos de uso e consequentes ameaças aos recursos naturais da UC, buscando com isso ter elementos que orientem estratégias de planejamento. Os usos conflitantes identificados na UC e consequentes ameaças aos recursos naturais são eminentes $e$ inobservante às leis ambientais, necessitando de intervenções urgentes para reverter o quadro de degradação. As paisagens da UC se mostram com potencialidades enquanto provedoras de serviços ecossistêmicos, o que justifica a necessidade de implementação da área protegida.
\end{abstract}

Palavras-chave: Usos Conflitantes, Valoração da Paisagem, Estratégias de Planejamento.

\begin{abstract}
This article refers to a study done in a Conservation Unity (CU) of integral protection, trying to offer planning orientations based on the study of the landscape evaluation. The Poeta e Repentista Juvenal de Oliveira's CU Park State in the city of Campina Grande - PB, has no management and needs scientific research to legitimate its implementation, because it is an unregulated $\mathrm{CU}$ which has to deal with other territoriality impositions. Thus, the main goal of this work was to identify and analyze the main conflicts of use and consequent threats to UC's natural resources, so that we have elements that could give us the right planning strategies. The conflicting uses identified in the $\mathrm{CU}$ and the consequent threatenings to the natural resources are eminent and unobservant to the environmental legislation, thus there must be urgent interventions so that the degradation setting can be reversed. The CU landscapes show themselves with great potentials as providers of ecosystem services, what justifies the necessity of the creation of a protected area.
\end{abstract}

Keywords: Conflicting Uses, Landscape Evaluation, Planning Strategies

\section{INTRODUÇÃO}

No Brasil, as Unidades de Conservação (UCs) são áreas protegidas, instituídas pelo poder público, cuja criação busca preservar a biodiversidade em ecossistemas de grande relevância ecológica e conservar paisagens de exuberante beleza cênica, além de garantir de forma sustentável a manutenção dos recursos naturais, importantes para a sobrevivência da espécie humana. 
As UCs são regidas pela Lei Federal de $n^{\circ} n^{\circ} 9.985 / 2000^{1}$, regulamentada pelo Decreto de $\mathrm{n}^{\circ}$ 4.340/2002, que instituiu o Sistema Nacional de Unidades de Conservação (SNUC) e estabeleceu critérios e normas para a criação, implantação e gestão, classificando essas áreas conforme os objetivos de manejo, sendo dividida em dois grandes grupos: Unidades de Uso Sustentável (UUS) e Unidades de Proteção Integral (UPI).

Os critérios específicos utilizados para criação dessas áreas são, geralmente, definidos pelos poderes executivos (federais, estaduais e municipais), mediante propostas de órgãos ambientais do governo, comunidade científica e, no geral, pelo anseio da sociedade civil organizada, institucionalizando essas áreas através de decretos.

No panorama atual, grande parte das UCs no país são criadas e não regularizadas, muitas sequer possuem Planos de Manejo $^{2}$, o que as tornam insuficientes para a proteção da biodiversidade e submetidas a diversos tipos de impactos ambientais. Adicionalmente, existem os problemas da falta de critérios ecológicos mais eficientes para a escolha da localização, delimitação e definição de tipologias de manejo mais adequadas a cada especificidade.

A categoria Parque do grupo UPI é a mais problemática. De acordo com Dios e Marçal (2009), “(...) muitos parques brasileiros são considerados 'parques de papel', ou seja, não efetivados" (p. 195), apenas existem através de decretos, mas não funcionam ou possuem sistemas regulatórios eficientes, ficando subordinados a diversos tipos de usos contrários aos seus objetivos.

Segundo Vallejo (2002), as decisões do governo na criação das UCs ainda se apresentam de forma deficiente pela ausência de mecanismos necessários para a sua efetivação e funcionamento, como a regulação fundiária, gestão de conflitos, elaboração de planos de manejo etc.

A UC Parque Estadual (PAREST) do Poeta e Repentista Juvenal de Oliveira (PRJO), conhecida como "Parque do Poeta", é um grande exemplo de UC não regularizada há mais de 13 anos. A UC foi instituída em 2004 pelo Decreto Estadual de $\mathrm{n}^{\circ} 25.322^{3}$, em uma área de 419 ha, sob caráter de urgência, porém, ainda não possui gestão e nos últimos anos vem sofrendo impactos de vários tipos de usos do solo, sobretudo da expansão da malha urbana, acarretando em degradações e ameaças aos seus recursos naturais e impossibilitando atingir seus objetivos de preservação.

Desse modo, o objetivo geral do artigo é identificar e analisar os principais conflitos de uso e consequentes ameaças aos recursos naturais da UC PAREST PRJO, e posteriormente apresentar

\footnotetext{
${ }^{1}$ Lei n ${ }^{\circ} 9.985$ da Constituição Federal do Brasil, de 18 de julho de 2000, que institui o Sistema Nacional de Unidades de Conservação. Fonte: http://www.planalto.gov.br/ccivil_03/leis/L9985.htm> acessado em junho de 2012.

${ }^{2}$ Documento técnico mediante o qual, com fundamento nos objetivos gerais de uma unidade de conservação, se estabelece o seu zoneamento e as normas que devem presidir o uso da área e o manejo dos recursos naturais, inclusive a implantação das estruturas físicas necessárias à gestão da unidade (SNUC, Lei 9.985, Art. 2 , Parágrafo XVII).

3 Diário Oficial da Paraíba, $\mathrm{n}^{\circ}$ 12.728, p. 1, João Pessoa, 10 de setembro de 2004. Disponível em < www.paraiba.pb.gov.br/diariooficial> Acesso em janeiro de 2015.
} 
as propostas das ações de intervenção para que se possa atingir a finalidade de preservação, com base nos dados da valoração da paisagem e nos usos compatíveis e adequados à uma UC de Proteção Integral.

O presente artigo trata-se de parte da dissertação ${ }^{4}$ de mestrado que buscou oferecer direcionamentos de planejamento e gestão dos recursos naturais da UC PAREST PRJO com base no estudo da valoração da paisagem, sob o viés da Geografia, levando em consideração as transformações territoriais que vêm ocorrendo nos últimos anos na área de estudo.

\subsection{Localização e caracterização da área de estudo}

A UC PAREST PRJO encontra-se localizada na zona periurbana do município de Campina Grande - PB, entre as coordenadas geográficas de $7^{\circ} 13^{\prime} 43,07^{\prime}{ }^{\prime} \mathrm{S} / 35^{\circ} 51^{\prime} 47,233^{\prime \prime} \mathrm{O}$ e 7¹3'16,70' S/3550'00,11'’O, situando-se à margem direita da BR 230 no sentido João Pessoa/Campina Grande, limitada a oeste pela malha urbana de Campina Grande e a leste pela zona rural do município de Massaranduba (figura 1).

\section{LOCALIZAÇÃO DA UC PARQUE ESTADUAL DO POETA E REPENTISTA JUVENAL DE OLIVEIRA}

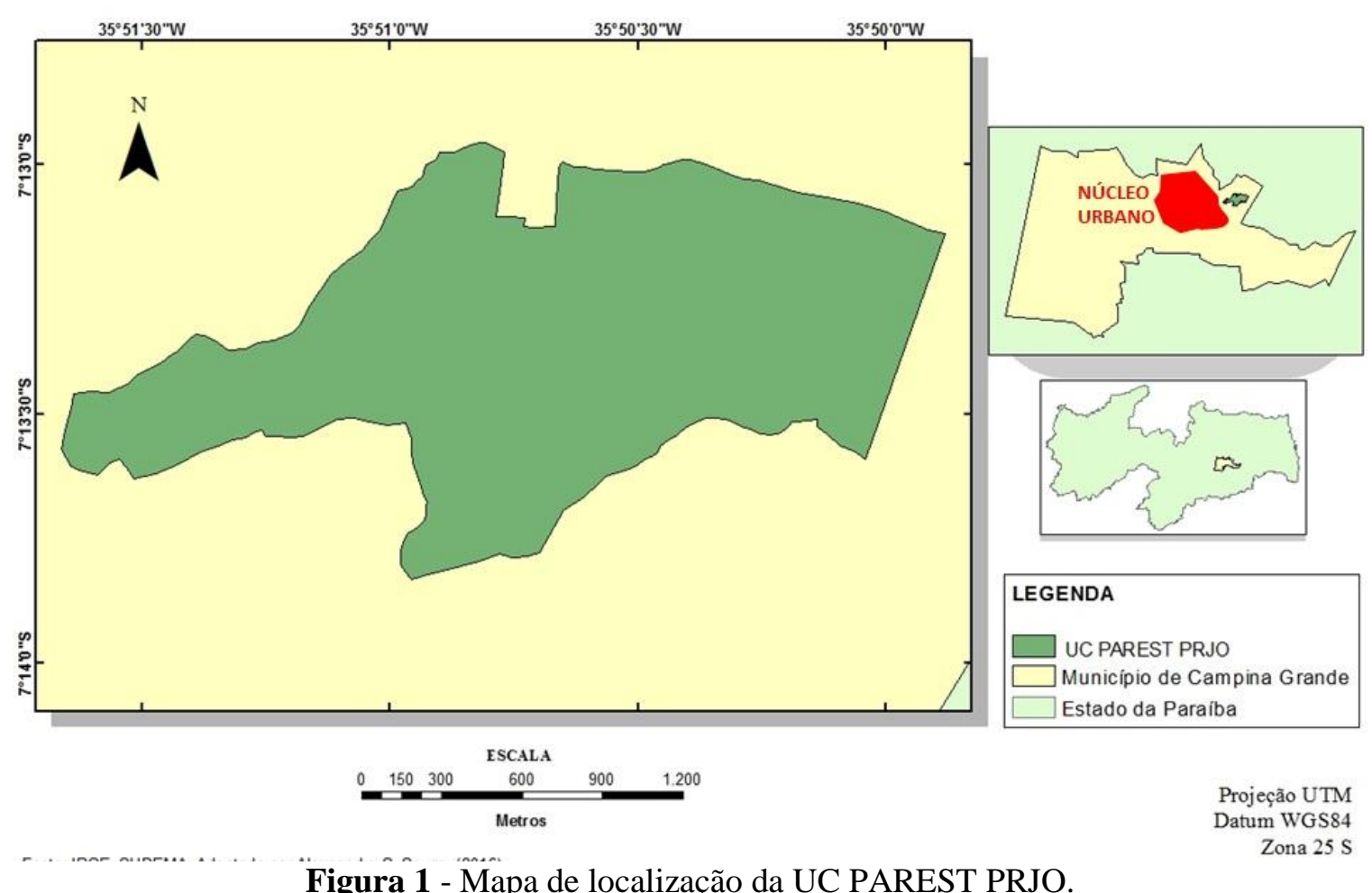

Fonte: Adaptado por Souza (2017).

\footnotetext{
${ }^{4}$ SOUZA, A. S. Valoração da Paisagem da Unidade de Conservação Parque Estadual do Poeta e Repentista Juvenal de Oliveira - Campina Grande - PB: proposta de ordenamento territorial. Dissertação de Mestrado, 2017, 256 p. (no prelo).
} 
Do ponto de vista natural em escala regional, a área de estudo está situada sobre o Planalto da Borborema e dentro dos limites de abrangência do clima Tropical Semiárido, na Zona de Transição Fitogeográfica do Agreste, mais precisamente no Agreste da Borborema (FELICIANO; MELO, 2003).

A fisionomia da vegetação que recobre a área pode ser caracterizada como de transição, composta por um bosque tropófilo que "transiciona" para um bosque xerófilo, sendo tal classificação realizada com base na proposta de Cámara (1997, 2005), com a presença predominante de espécies do Bioma Caatinga (SOUZA, 2017).

Em escala local, a UC encontra-se sobre parte de um batólito granítico como rocha preponderante, que faz parte do Complexo de Campina Grande (CCG) (ALMEIDA, 1997), situada num patamar de relevo mais rebaixado e mais dissecado, correspondendo a uma área de vale que é cortada no seu limite oeste pela drenagem do Riacho das Piabas.

Os solos predominantes na área são os Neossolos Litólicos Eutróficos e Vertisol, Solonetz Solodizado, com maior preponderância, e o afloramento de rocha (AESA, 2006).

A paisagem da UC é fisionomicamente geodiversa, possuindo ecossistemas com variados tipos de habitats que possibilita uma diversidade de animais e plantas coexistirem, desempenhando funções ecossistêmicas importantes, além de apresentar esteticamente um contraste com as paisagens circundantes bastante antropizadas, conforme se observa na figura 2.

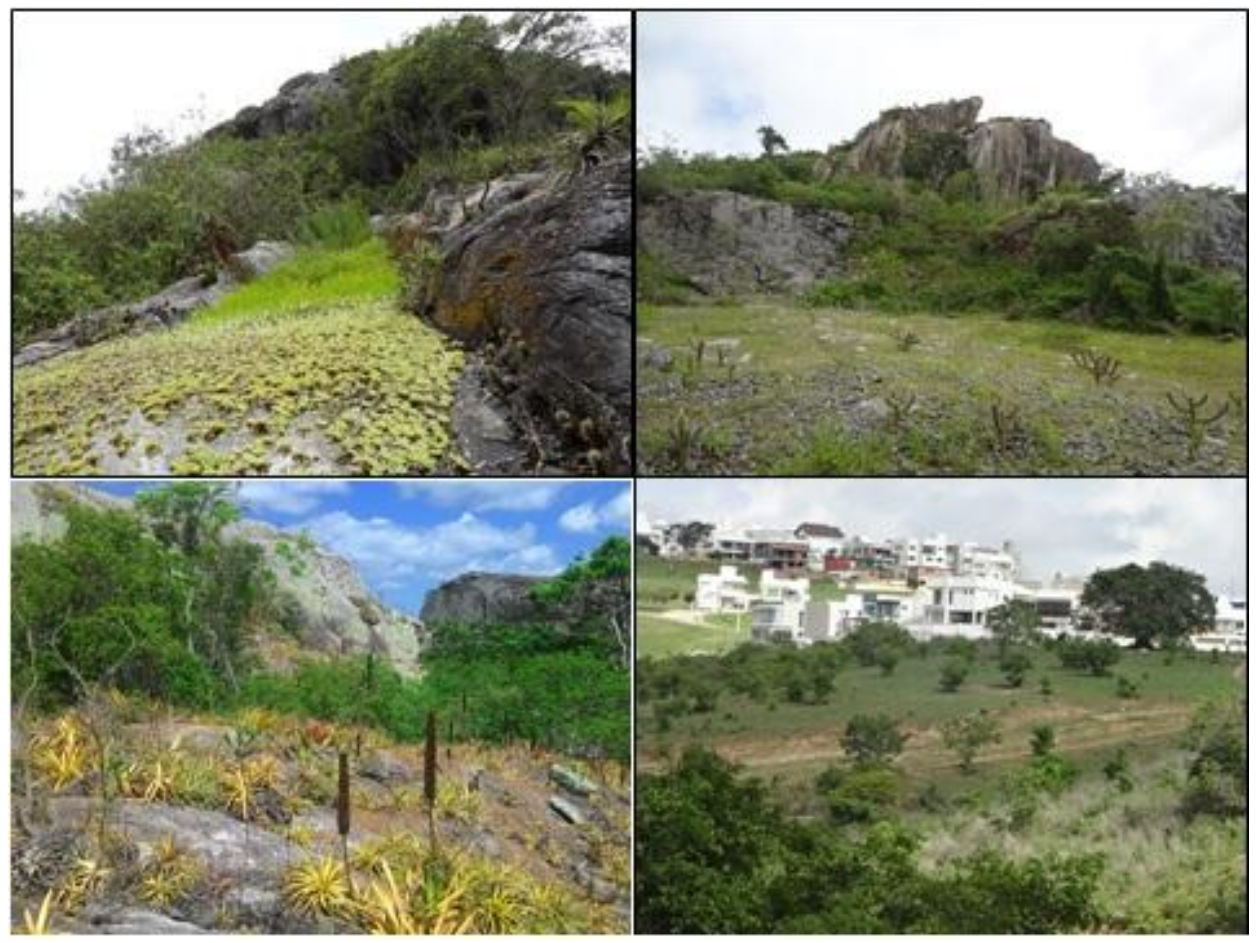

Figura 2 - Fotografia de algumas paisagens na área da UC.

Fonte: Registro de campo, por Robson Oliveira. 
Sua maior referência se dá pelas formações rochosas que compõem a paisagem, muito utilizadas para a prática de esportes de aventura, como o alpinismo, possuindo diversas vias de escalada vertical e sendo um referencial a nível regional para a prática deste esporte, além de outros como trekking, camping e mountain bike.

\section{METODOLOGIA}

Foi realizado levantamento e revisão bibliográfica para a construção teórica e metodológica da pesquisa, pesquisa documental em órgãos governamentais, tais como: Secretaria de Planejamento (SEPLAN) da Prefeitura Municipal de Campina Grande (PMCG) e Superintendência de Administração do Meio Ambiente (SUDEMA), com o objetivo de coletar documentos relacionados aos decretos de criação da UC PAREST PRJO e informações sobre a área de estudo.

Foram realizadas entrevistas semiestruturadas com a coordenadora dos Estudos Ambientais do setor responsável pela gestão de UCs na Paraíba e com proprietários de terras, trabalhadores arrendatários e/ou moradores de condição na área de estudo. Tais entrevistas tiveram o objetivo de conhecer os tipos de uso do solo, formas de manejo, condições de trabalho, usos conflitantes de acordo com a legislação ambiental, situação fundiária e história local.

Utilizou-se o material cartográfico dos limites da UC adaptados por Souza (2012), assim como uma adaptação do mapa planialtimétrico cadastral da área, produzido pela ATECEL (2004) no ato de criação da UC.

As técnicas de mapeamento utilizadas tiveram como suporte os Sistemas de Informações Geográficas (SIG). Foi criada uma base de dados digital no software gratuito Spring 5.3, onde foram elencados planos de informações com dados Georreferenciadas da área de interesse e em seguida produzidos mapas temáticos que auxiliaram na compreensão do contexto da área de estudo.

Foi elaborado um mapa do uso e ocupação do solo da UC PAREST PRJO, através da técnica de sensoriamento remoto on screen, a partir de imagem aérea de alta resolução com data de abril de 2015, adquirida através do software Google Earth versão Profissional, e com base nos dados do mapa planialtimétrico cadastral da área da UC (ATECEL, 2004), além das observações em campo, possibilitando a produção de um mapa mais próximo à realidade.

Os procedimentos metodológicos adotados para se atingir o objetivo geral se basearam em alguns parâmetros e indicadores predefinidos, como a identificação dos principais tipos de usos do solo contrários ao que se estabelece no SNUC para uma UC do tipo UPI e dos indicadores relacionados aos tipos de ameaças exercidas sobre a paisagem, sobretudo como consequências dos 
usos conflitantes, como a pressão demográfica, impactos por atividades de uso direto dos recursos naturais, transitividade/acessibilidade aos fragmentos e ameaças alternativas, como poluição sonora, desmatamento, contaminação do lençol freático, queimadas etc., baseando-se no parâmetro dos coeficientes de ameaça da metodologia LANBIOEVA de Valencia et. al. (2015b).

Foram definidos dois níveis de ameaças com base nos tipos de usos conflitantes, com o intuito de auxiliar na tomada de decisões para a elaboração do zoneamento dos usos compatíveis aos objetivos de uma UC do tipo UPI, onde:

- Ameaça preocupante: quando um tipo de uso conflitante não causa danos irreversíveis aos recursos naturais, sendo possível de ser controlado ou solucionado em um curto prazo, através de ações educativas ou mitigadoras.

- Ameaça muito preocupante: quando um tipo de uso conflitante causa danos irreversíveis aos recursos naturais, não sendo possível de ser controlado ou mitigado em um curto prazo.

A condição de ameaça foi definida como a influência do impacto negativo que determinados tipos de usos conflitantes oferecem às unidades de paisagem, tais como isolamento, perturbação a biota, desmatamento etc.

A partir do mapa de uso e ocupação do solo, cartografou-se as áreas dos principais usos conflitantes.

Foram utilizados os dados da valoração da paisagem da UC PAREST PRJO obtidos por SOUZA (2017), mediante aplicação da metodologia LANBIOEVA (acrônimo para Landscape Biogeographic Evaluation), especificamente o mapa do parâmetro global de Prioridade de Conservação (PRICON), para a identificação das áreas e posteriormente indicar as formas de intervenção e uso.

A LANBIOEVA se trata de uma metodologia integrada, criada por Valencia et. al. (2015b), focando no estudo da vegetação como elemento principal, buscando levantar aspectos intrínsecos da flora e caracterizar, avaliar, valorar e cartografar unidades de paisagem de um determinado território de forma qualitativa, baseando-se em critérios de ordens naturais, culturais e coeficientes de ameaça, se sustentando em dois conceitos valorativos diferenciados: Interesse de Conservação (INCON) e Prioridade de Conservação (PRICON).

Partindo de uma análise crítica dos valores biogeográficos de PRICON, a elaboração do zoneamento de usos compatíveis se baseou na Lei do SNUC, que estabelece critérios de uso em UCs do tipo Parque, e nas atividades que já vêm sendo desenvolvidas por diversos grupos na UC PAREST PRJO e áreas adjacentes. 


\section{RESULTADOS E DISCUSSÕES}

Como a UC PAREST PRJO foi criada e não regulamentada, obviamente que quaisquer atividades exercidas na área que não estejam de acordo com os objetivos da lei do SNUC para UCs do tipo UPI serão consideradas conflitantes. Porém, o que se busca demonstrar no artigo é a identificação e análise dos principais conflitos de uso e fatores que contribuem na degradação dos recursos naturais da UC e impedem a sua regulamentação, motivados por questões relacionadas à falta de políticas públicas ambientais mais efetivas, de elaboração e aplicação de um plano de manejo para a UC e, por conseguinte, da falta de uma maior preocupação do Poder Público local com a preservação e conservação de áreas com potencial paisagístico e ecossistêmico.

\subsection{Contextualizando a problemática da UC PAREST PRJO}

A partir de levantamentos realizados junto ao órgão gestor das UCs na Paraíba, a Superintendência de Administração do Meio Ambiente (SUDEMA) ${ }^{5}$, constatou-se a falta de informações sobre a UC PAREST PRJO. Entretanto, o órgão reconhece a sua existência institucional e principais problemas que impedem a efetivação. Segundo a coordenadoria de Estudos Ambientais, ainda não há uma execução de estratégias de gestão e fiscalização efetiva na UC, devido às várias limitações institucionais, dentre elas a carência de agentes fiscalizadores e posicionamento mais efetivo do governo estadual em regularizá-la.

Analisando os documentos de criação da UC PAREST PRJO, inicialmente percebeu-se deficiências e contradições durante e após o ato de sua criação, conforme inicialmente apontado por Souza (2012). As deficiências se referem ao não cumprimento de vários requisitos legais exigidos para a criação de UCs, como por exemplo o estudo de impactos socioambientais, a consulta pública, uma discussão sobre qual categoria seria a mais adequada, a regularização fundiária da área, a criação do Plano de Manejo etc. (SNUC, 2002).

Nesse sentido, Pádua (2002) faz diversas críticas às formas como se têm criado as UCs no país, nos níveis federais, estaduais e municipais, principalmente após a lei do SNUC, pois o Estado as criam sem base técnica e científica e muitas vezes até sem necessidade. Além disso, grande parte das categorias de manejo são aplicadas inadequadamente às realidades, gerando conflitos, além de muitas dessas categorias possuírem objetivos semelhantes entre si, causando confusão nos gestores.

\footnotetext{
${ }^{5}$ SUDEMA - Superintendência de Administração do Meio Ambiente. Site: http://www.sudema.pb.gov.br/
} 
Subjacente a essas questões, um ponto fundamental que enaltece as principais ameaças e conflitos de uso na UC PAREST PRJO é com relação a falta de gestão e a não regulamentação da situação fundiária da área, como determina a Lei do SNUC no caso de UCs do tipo Parque.

De acordo com alguns relatos de moradores da área de estudo, quando foi anunciado que naquele espaço seria criada uma UC ocorreu um sentimento de inquietação entre os proprietários das terras, pois havia a possibilidade de retirada das populações e indenização das terras. Como o Estado não cumpriu o prometido e devido ao sentimento de dúvidas, alguns dos proprietários venderam suas terras.

Sobre essas questões, Dios e Marçal (2009) afirmam que devido à demora na regulamentação fundiária das UCs públicas, há um considerável aumento das degradações, pois os proprietários das terras acabam acelerando a forma de exploração dos recursos naturais, executando práticas danosas ao meio pela ciência de que a qualquer momento poderão ser impedidos. Em outros casos, constroem benfeitorias para tentar justificar o uso e permanência da terra e, assim, dificultar a regulamentação e garantir maior rentabilidade no momento da indenização.

Atualmente, o uso do solo da UC PAREST PRJO é basicamente a pequena agricultura e pecuária de subsistência e a extração de minério, porém esse último apenas pontualmente. Há famílias que residem no interior da UC e nas suas adjacências, como é o caso de algumas pequenas chácaras e a comunidade de Várzea Grande, essa última localizada à norte fora dos limites da UC. Além dessas, há também parte do condomínio Alphaville localizado dentro dos limites oeste da UC.

A implementação legal do Parque traria impactos sobre essas populações e atividades, uma vez que a tipologia da UC é excludente das ações humanas de forma direta e limita o uso e ocupação no entorno (Zona de Amortecimento ${ }^{6}$ ), muito embora diversos estudos têm demonstrado que a permanência de populações tradicionais no interior das UCS colabora na conservação e preservação da natureza (PÁDUA, 2002).

Nesse sentido, torna-se importante considerar os impactos em que as UCs causam aos lugares, pois além do discurso da necessidade de preservação e conservação da natureza, é preciso estar ciente de que as territorialidades possuem dinâmicas e interesses diversos, que em muito dos casos são antagônicas às questões ambientais, sendo necessário que a gestão da UC busque conscientizar e envolver a sociedade de forma participativa no que tange as tomadas de decisões.

\footnotetext{
${ }^{6}$ De acordo com o Art. 25 da Lei 9.985/2000 do SNUC, são as áreas do entorno de uma unidade de conservação (exceto APA e RPPN), onde as atividades humanas estão sujeitas a normas e restrições específicas, com o propósito de minimizar os impactos negativos sobre a unidade
} 
No entanto, grande parte das terras da UC não são utilizadas, algumas estando em pousio social devido à alta especulação imobiliária local, enquanto outras são áreas de reserva legal, APPs e terrenos pedregosos e irregulares, que dificultam a sua utilização.

Segundo Pádua (2002), há uma necessidade de inserir as UCs dentro de um processo de desenvolvimento econômico local, gerando renda para as populações locais, principalmente para os que estão inseridas dentro das UCs ou que sofreram ou sofrem o impacto da sua criação. Ainda de acordo com a autora, as políticas públicas responsáveis por áreas protegidas devem unir suas intenções às das políticas setoriais, como a de turismo e lazer, educação, desenvolvimento local e regional, desenvolvimento científico e entre outras, tornando seus objetivos interligados.

Outras questões bastantes discutíveis são com relação a atual delimitação do perímetro da UC PAREST PRJO, pois percebe-se que não respeita alguns condicionantes ambientais e territoriais, necessários para uma maior proteção dos recursos naturais.

Em 2010, o decreto de criação da UC PAREST PRJO foi alterado para o atual de $n^{\circ}$ 31.1267, alterando seus limites e mudando o nome da UC para "Parque Estadual do Poeta e Repentista Juvenal de Oliveira". Segundo Souza (2012), os limites do Parque foram diminuídos em cerca de $37,6 \%$, possuindo atualmente $261,90 \mathrm{ha}$, conforme pode ser observado na figura 3.

\section{ALTERAÇÕES DA ÁREA DA UC PAREST PRJO}

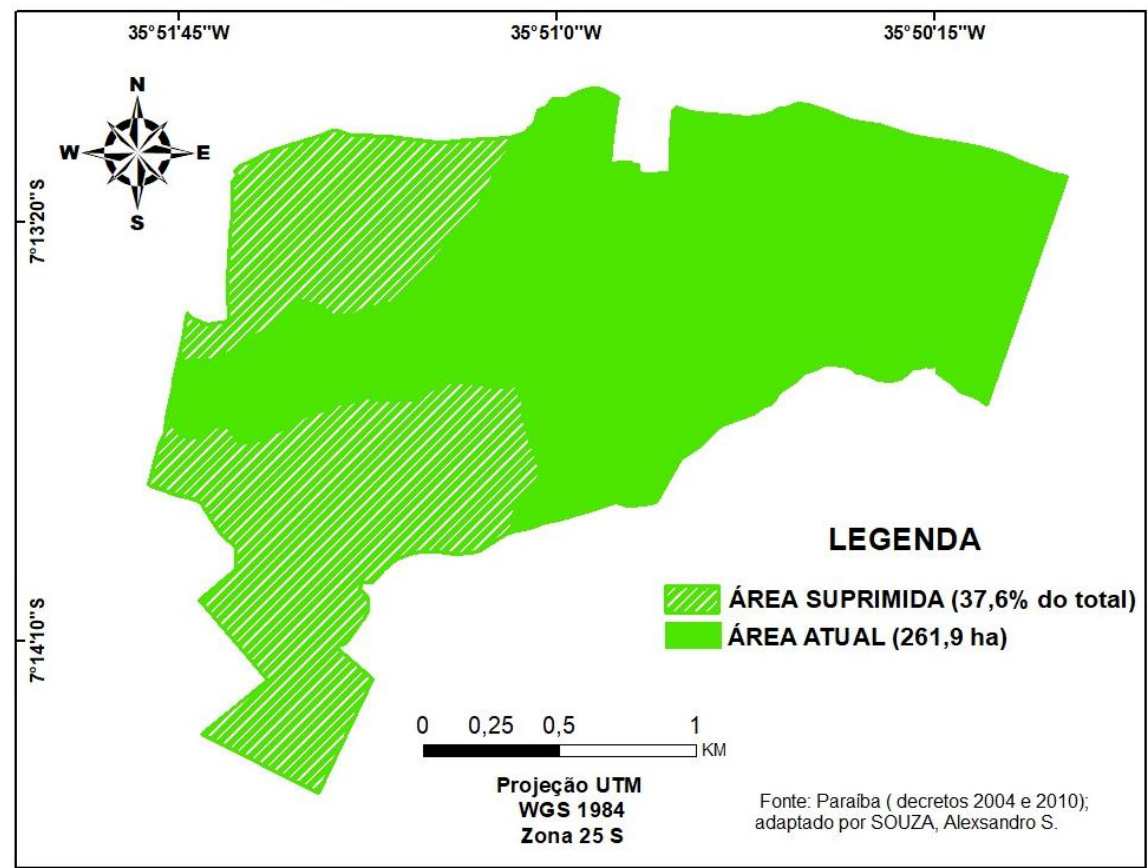

Figura 3 - Ilustração da alteração dos limites do Parque, com base nos dados dos antigos limites de 2004 e no atual de 2010, disponibilizado nos decretos publicados no Diário da União. Fonte: Paraíba (2004 e 2010); adaptado de Souza (2012).

\footnotetext{
${ }^{7}$ PARAÍBA. Altera o Artigo $1^{\circ}$ do Decreto $n^{\circ} 25.322$, de 09 de setembro de 2004, com a denominação Parque Estadual do Poeta e Repentista Juvenal de Oliveira, e dá outras providências. Diário Oficial da Paraíba, no ${ }^{\circ}$ 14.312, p. 1, João Pessoa. Disponível em < www.paraiba.pb.gov.br/diariooficial> Acesso em janeiro de 2015.
} 
Na redelimitação da UC em 2010, suprimiu-se parte das Áreas de Preservação Permanente (APP) e grande parte dos terrenos próximos a malha urbana, ambos a oeste da UC. Entretanto, os limites a leste, onde se localizam as áreas mais conservadas e distantes da pressão urbana e com características físico-ambientais que justificam a criação da UC, não sofreram quaisquer alterações e nenhuma área foi incluída na nova delimitação para compensar o que foi suprimido.

Houve na verdade a supressão das áreas da UC mais próximas ao núcleo urbano para atender aos interesses privados, a exemplo da construção do condomínio Alphaville dentro dos antigos limites da UC, que gerou denúncias ao Ministério Público Estadual (SOUZA, 2012).

Analisando o Plano Diretor do município de Campina Grande PDCG (2006), percebe-se que à oeste da malha urbana onde se localiza parte da UC é considerada como Zona de Ocupação Dirigida (figura 4), ou seja, o uso e a ocupação do solo sofrem restrições à intensificação por inexistirem condições físicas favoráveis e equipamentos urbanos instalados.

\section{Mapa do Plano Diretor de Campina Grande - 2006}

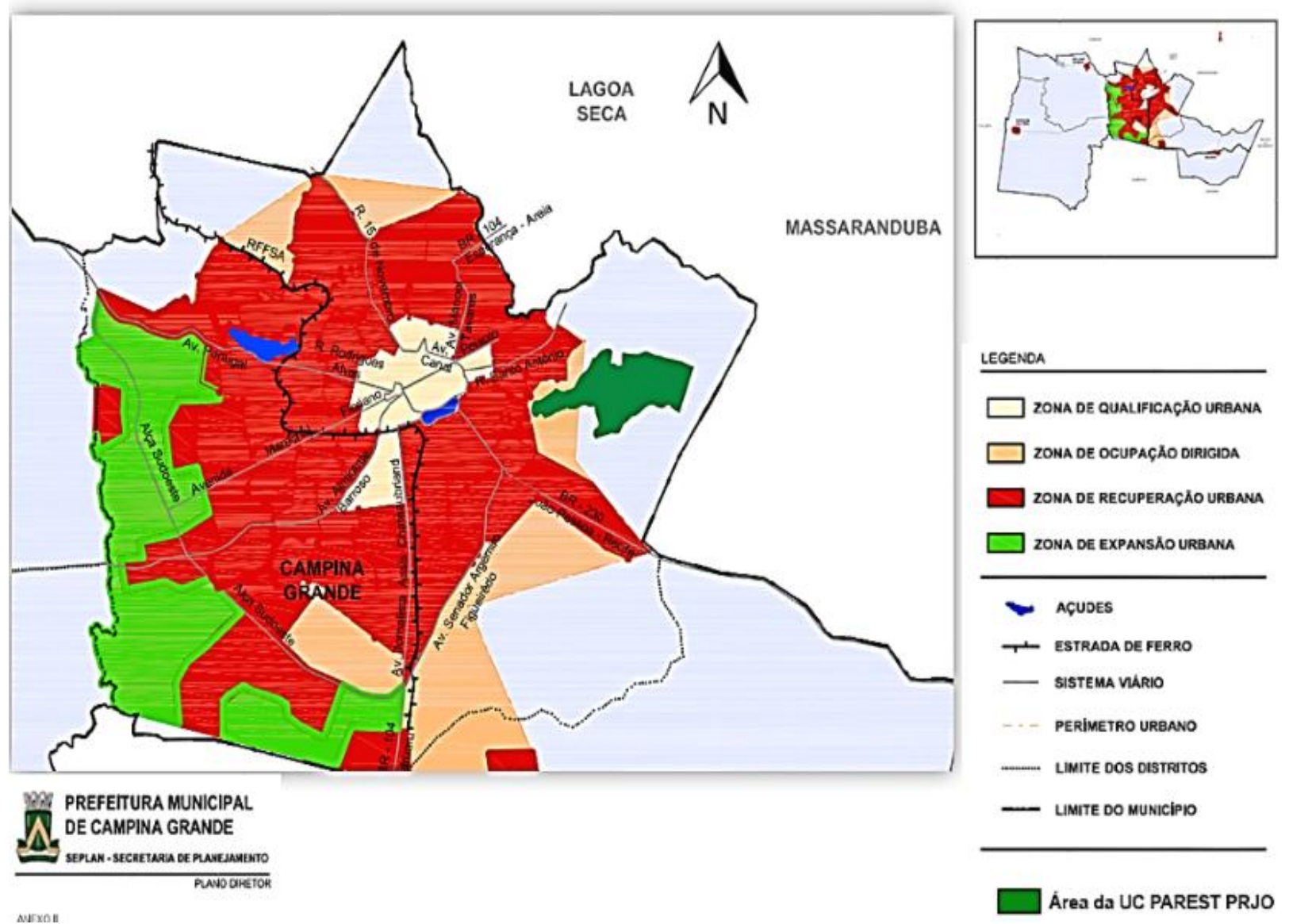

Figura 4 - Recorte do mapa do Plano Diretor de Campina Grande de 2006, ressaltando o núcleo urbano, as zonas estratégicas do plano e a localização da UC PAREST PRJO. Fonte: PMCG-SEPLAN (2006), adaptado pelo autor. 
Atualmente observa-se uma clara redefinição dessa zona, orquestrada pelo Poder Público e iniciativa privada, com a construção de infraestrutura urbana, loteamentos e habitações, muito embora ainda se mantenha o objetivo implícito de ordenar a ocupação de forma restritiva.

A Prefeitura Municipal de Campina Grande (PMCG) está executando no local uma obra de infraestrutura urbana que adentra os limites da UC PAREST PRJO, projeto este denominado de Alça Leste, se tratando da construção de uma grande estrada larga e asfaltada, em fase de operação desde o ano de 2015. De acordo com o projeto, a estrada tem como intuito facilitar o acesso à região do Brejo Paraibano e diminuir o tráfego de veículos na zona central da cidade (PMCG, 2013).

Embora o objetivo oficial do projeto seja o de melhorar a mobilidade urbana no município, observa-se que o interesse também é o de subsidiar projetos privados de construção de condomínios residenciais na área, desconsiderando as questões ambientais e o respeito à Lei.

Quanto a essas questões, Júnior, Coutinho e Freitas (2009) colocam que esse tipo de problema é devido o vetor de conflito da ordem das municipalidades, ou seja:

Como os governos municipais estão sujeitos a pressões concretas dos interesses locais e com o poder de definir o ordenamento territorial, é muito comum que decisões tomadas firam a legislação federal de meio ambiente, gerando intermináveis batalhas jurídicas. Trata-se de questão delicada do ponto de vista da gestão, já que muitas unidades de conservação enfrentam a disposição dos governos municipais de expandir suas áreas urbanas para áreas do entorno das unidades existentes (p. 59).

Dessa forma, observa-se que as ações de ordenamento territorial orquestrada pelo Poder Público são contraditórias e conflitantes entre si, pois ora almejam objetivos de proteger a natureza de forma integral, no caso da ideia de criação da UC PAREST PRJO, e outrora possibilitam um tipo de desenvolvimento que ameaça de forma ativa a integridade dos recursos naturais, em um município com elevado déficit de áreas verdes.

\subsection{Conflitos de uso e ameaças à paisagem da UC PAREST PRJO}

A localização da UC PAREST PRJO é um grande desafio ante a pressão antrópica, devido à proximidade do núcleo urbano, sendo este um dos mais graves problemas que afetam a paisagem do lugar e ameaçam a manutenção dos fragmentos de vegetação e a biodiversidade local.

Outras atividades de uso predatório dos recursos naturais, tais como o desmatamento, extração de minério, atividades agrícolas de subsistência e pecuárias tradicionais, são realizadas 
comumente dentro da área da UC e no seu entorno, e acabam descaracterizando a paisagem e prejudicando o alcance dos objetivos da UC, comprometendo os poucos fragmentos existentes.

O mapa de cobertura e uso do solo atual da UC PAREST PRJO pode oferecer uma compreensão da distribuição das atividades de uso do solo realizadas atualmente no seu interior, assim como a disposição de alguns recursos naturais e áreas com solo exposto, conforme pode ser visualizado na figura 5 .

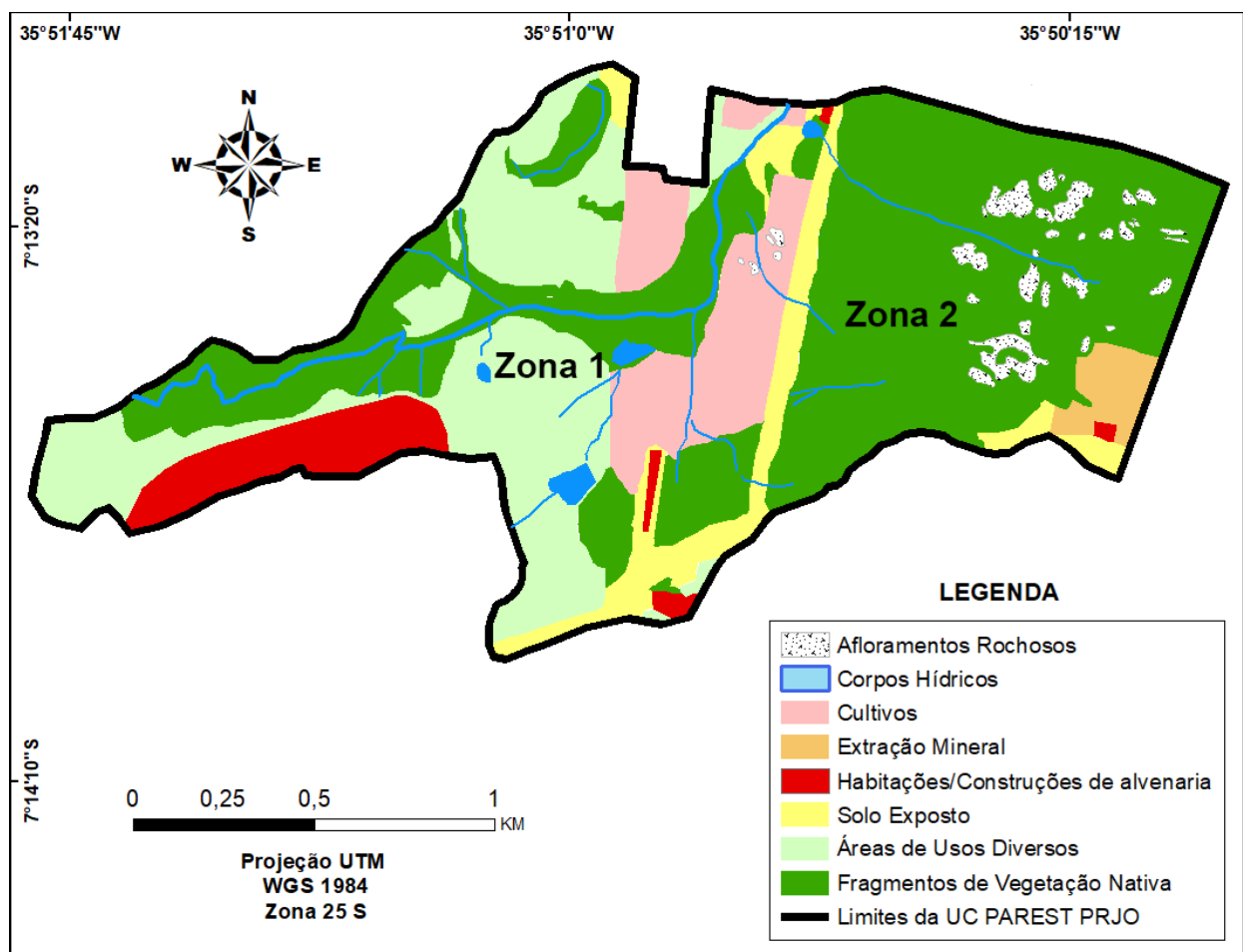

Figura 5 - Mapa de cobertura e uso do solo da UC PAREST PRJO, ano 2017. Fonte: SOUZA (2017).

Como se observa na figura 5, atualmente as atividades de uso e ocupação do solo na UC são realizadas em maior extensão e intensidade na Zona 1, enquanto que na Zona 2 o uso é menos intenso e em menor extensão, possibilitando perceber essas diferenças na cobertura dos fragmentos de vegetação nativa em ambas as zonas.

O quadro 1 seguir tem a função de mostrar os tipos de conflitos de uso na UC, ameaças e tipos de impactos a qualidade da paisagem da área de estudo, de acordo com cada zona.

Quadro 1 - Principais tipos de conflitos de uso na UC PAREST PRJO e ameaças e impactos sobre os recursos naturais da área de estudo.

\begin{tabular}{|c|c|c|}
\hline & ZONA 1 & ZONA 2 \\
\hline $\begin{array}{l}\text { Conflitos } \\
\text { de uso }\end{array}$ & $\begin{array}{l}\text { - Cultivos; } \\
\text { - Criação de gado; } \\
\text { - Construção de estrada; } \\
\text { - Habitações; }\end{array}$ & $\begin{array}{l}\text { - Mineração; } \\
\text { - Construção de estrada; }\end{array}$ \\
\hline
\end{tabular}




\begin{tabular}{|c|c|c|}
\hline Ameaças & $\begin{array}{l}\text { - Biota (bosques, mata ciliar, } \\
\text { cercas vivas, fauna); } \\
\text { - Solo; } \\
\text { - Estabilidade das encostas; } \\
\text { - Afloramentos rochosos. }\end{array}$ & $\begin{array}{l}\text { - Solo; } \\
\text { - Biota (bosques, cercas } \\
\text { vivas, fauna); } \\
\text { - Afloramentos rochosos; } \\
\text { - Paisagem. }\end{array}$ \\
\hline Impactos & $\begin{array}{l}\text { - Desmatamento do } \\
\text { fragmento florestal da Mata } \\
\text { dos Aranhas, da Mata Ciliar } \\
\text { do Riacho das Piabas e } \\
\text { retirada das cercas vivas; } \\
\text { - Comprometimento do solo } \\
\text { pela erosão; } \\
\text { - Alteração da morfologia do } \\
\text { terreno; } \\
\text { - Acessibilidade e } \\
\text { transitividade intensa dentro } \\
\text { dos fragmentos; } \\
\text { - Assoreamento de corpos } \\
\text { hídricos. }\end{array}$ & $\begin{array}{l}\text { - Comprometimento do } \\
\text { solo pela erosão; } \\
\text { - Desmatamento do } \\
\text { fragmento florestal da } \\
\text { Mata da Pedra do } \\
\text { Urubu; } \\
\text { - Perturbação aos } \\
\text { ecossistemas associados; } \\
\text { - Descaracterização da } \\
\text { paisagem; } \\
\text { - Acessibilidade e } \\
\text { transitividade intensa } \\
\text { dentro dos fragmentos. }\end{array}$ \\
\hline
\end{tabular}

Observa-se no quadro 1 que os usos conflitantes ocorrem com maior intensidade na zona 1, como os cultivos, a criação de gado e as habitações, conforme pode ser visualizado na figura 5. Essa maior ocorrência se deve por se tratar de uma área historicamente antropizada, além de fazer fronteira com os limites urbanos da cidade. O mapa de usos conflitantes e ameaças aos recursos naturais da UC oferece uma compreensão melhor da espacialidade dessas áreas, conforme visualizado na figura 6 . 


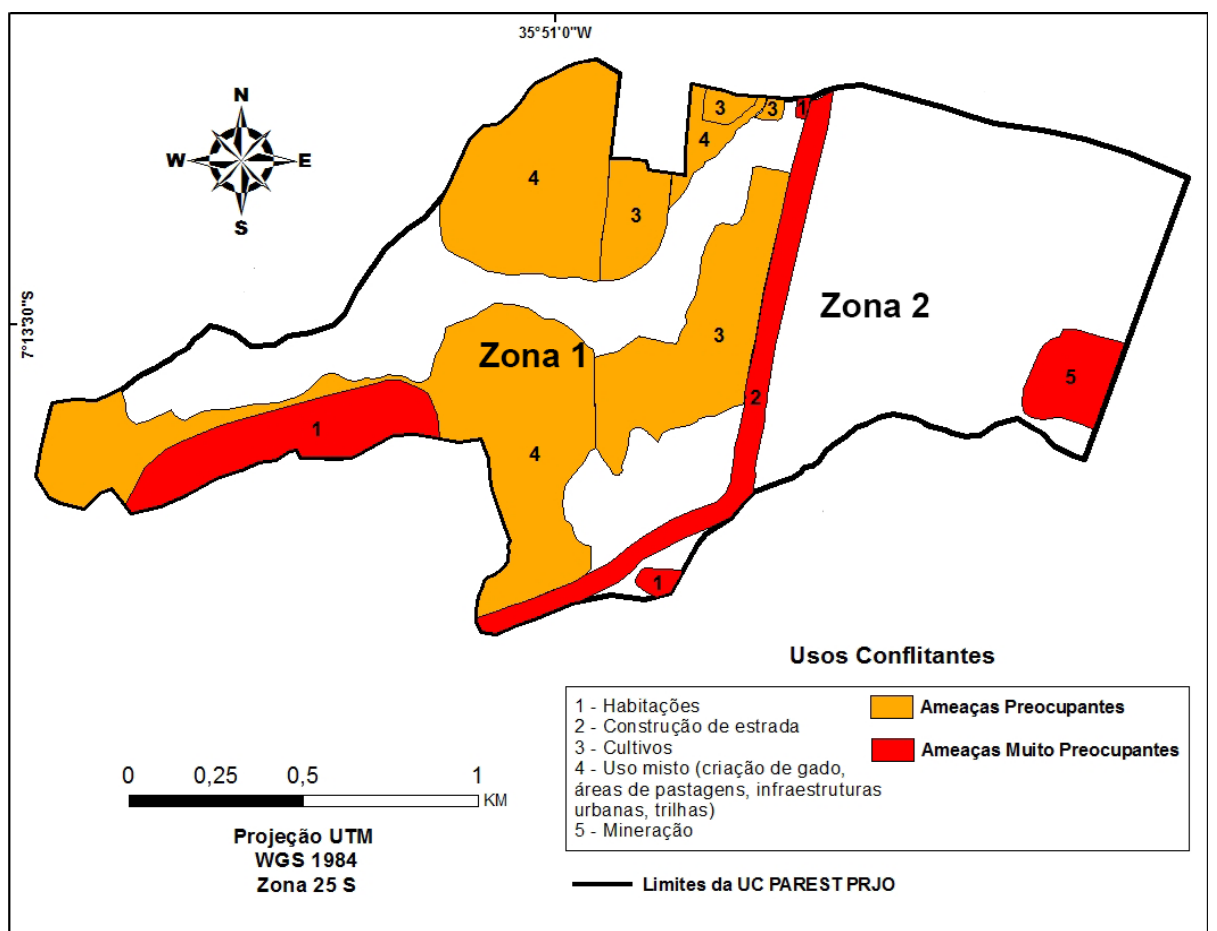

Figura 6 - Mapa de Usos Conflitantes no interior da UC PAREST PRJO, ano 2017. Fonte: Souza (2017).

Entretanto, grande parte dos conflitos de uso localizados no interior da zona 1 não ameaçam definitivamente os recursos naturais, mas que são ameaças preocupantes e que necessita de medidas de mitigação dos efeitos desses usos, como por exemplo o incentivo à aplicação do sistema agrosilvopastoril para as atividades agrícolas e pecuárias, recuperação da vegetação nativa, controle e restrição das atividades potenciais de riscos ligadas as habitações e infraestruturas urbanas, fiscalização constante da expansão urbana em locais mais preservados, etc.

Já os conflitos de usos na Zona 2 são poucos, porém os existentes causam ameaças muito preocupantes, sendo difícil de reverter a curto prazo o impacto causado sobre os recursos naturais, como a exploração de granito, por exemplo, devido a transformação espacial em que tal atividade impõe ao ambiente.

Vale enfatizar que as ameaças constatadas nas Zonas 1 e 2 são os resultados dos usos antagônicos aos objetivos da UC, como a exploração dos recursos naturais de forma direta e a ocupação do solo de forma inobservante ao que rege a Lei do SNUC.

Com relação aos conflitos de uso, a Zona 1 possui habitações pontualmente localizadas dentro da área da UC, sendo uma questão a ser resolvida do ponto de vista legal, já que é proibido por lei a sua permanência em UCs do tipo UPI, apesar de já ter havido uma redelimentação da UC em 2010 para contornar esse problema, quando foi construído o condomínio Alphaville dentro dos limites. 
Habitações próximas a UCs de proteção integral são ativos de impactos ambientais, pois a possibilidade é eminente de problemas ocasionados por vazamentos de esgoto, gás, água etc., incêndios, contaminação da biota, dispersão de espécies exóticas, invasões de animais silvestres nas residências etc., devendo haver restrições de uso na zona de amortecimento, conciliando a preservação com o uso racional da área de entorno.

O projeto Alça Leste, como abordado anteriormente, pode ser considerado um dos maiores conflitos de uso e atividade que ameaça e gera impacto ambiental sobre os recursos naturais das Zonas 1 e 2, adentrando os atuais limites da UC no sentido norte-sul. É um tipo de uso e ameaça muito preocupante que possibilita a descaracterização de toda a paisagem ao seu redor, embora seja uma infraestrutura que pode beneficiar o acesso logístico a UC PAREST PRJO.

A abertura de terrenos para construção das vias tem contribuído para o desflorestamento de parte do fragmento Bosque Tropófilo Mata dos Aranhas na zona 1, além da derrubada de cercas "vivas" e remoção de afloramentos através de explosivos, ocasionando o corte de espécies de vegetação de caatinga ameaçados de extinção (figura 7) e perturbações sonoras dentro da UC.

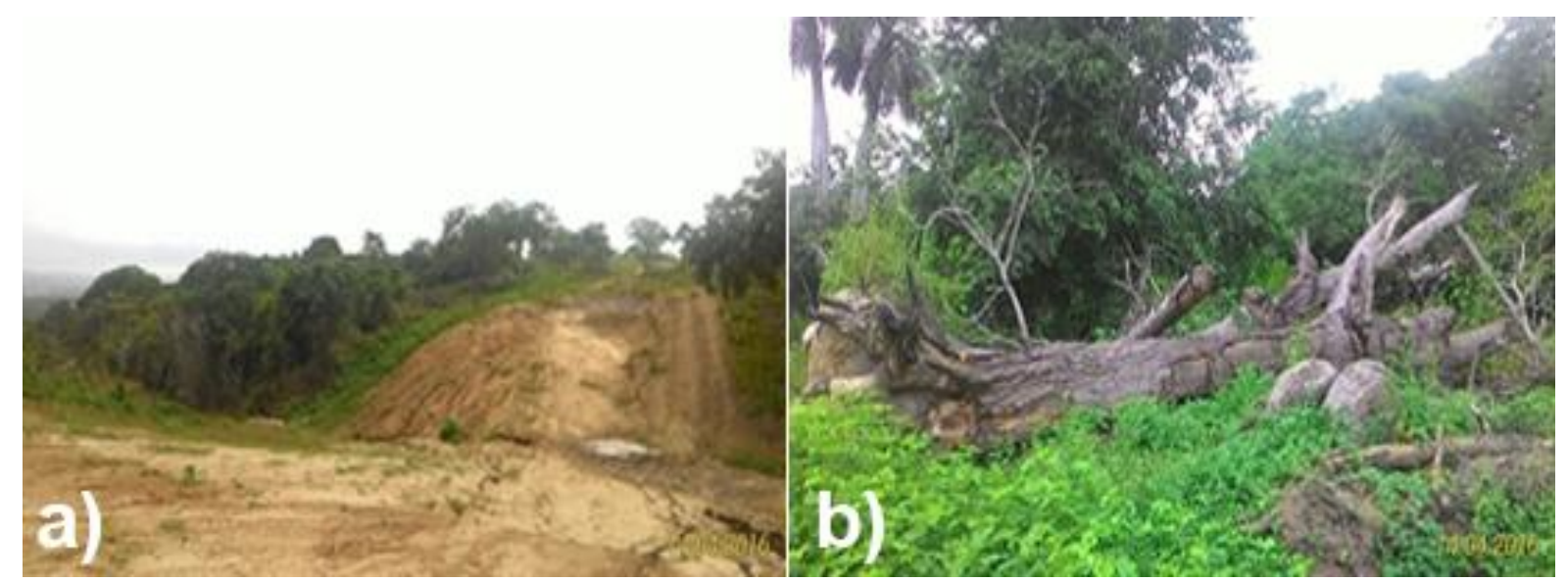

Figura 7 - a) Trecho de abertura para construção de estrada da Alça Leste, situado ao lado do fragmento BTA 1 (Mata dos Aranhas); b) Árvore da espécie Schinopsis brasiliensis Engl., derrubada por máquina pesada. Fonte: Registro de campo, por Alexsandro S. Souza.

O projeto não levou em consideração as características ecológicas da área, uma vez que está isolando os fragmentos florestais de grande importância biológica.

Outra questão é que o material utilizado para a terraplanagem da estrada está sendo retirado de um local dentro da UC, na zona 2, próximo ao fragmento Bosque Tropófilo Arbóreo 2 (Mata da Pedra do Urubu), em uma área aproximada de 20 hectares, ocasionando a descaracterização da paisagem e comprometimento do solo (figura 8). 


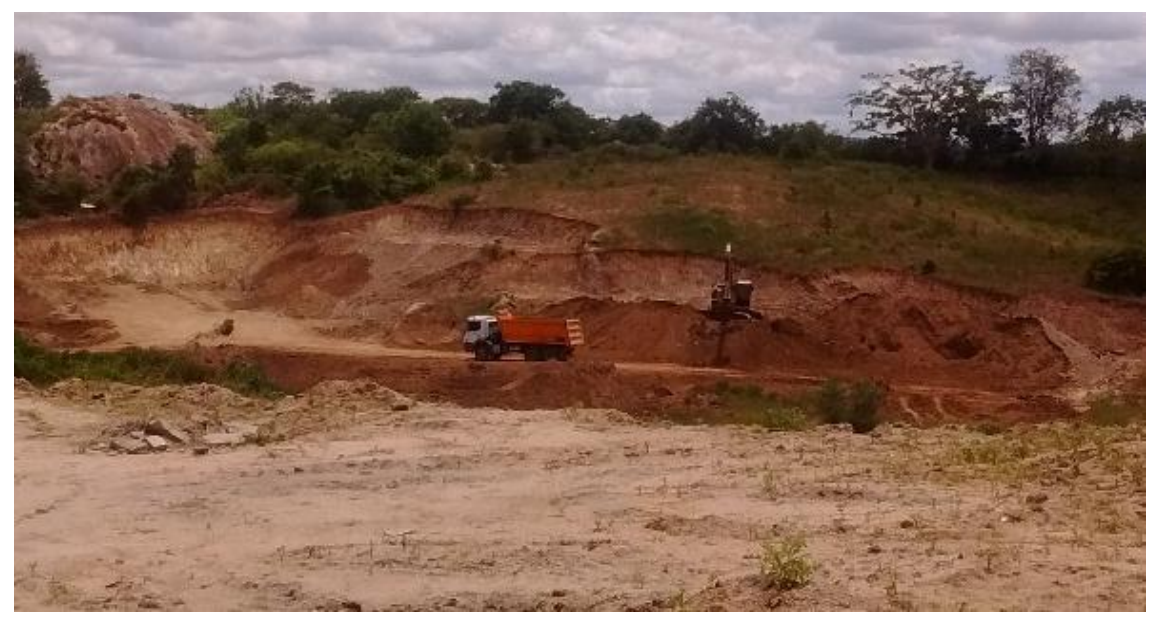

Figura 8 - Fotografia tomada de dentro da área da UC, com destaque para a degradação provocada pela extração de saibro. Fonte: Registro de campo, por Alexsandro S. Souza.

Além da retirada do material para terraplanagem, haverá a extração de granito próximo ao local e reativação de uma antiga pedreira para o processamento da rocha que será utilizada na pavimentação asfáltica da estrada, possuindo autorização do próprio órgão gestor da UC PAREST PRJO.

Esse tipo de uso conflitante e de grande ameaça aos recursos naturais é bastante controverso e contrário ao que estabelece a lei do SNUC, pois a UC PAREST PRJO trata-se de uma categoria de unidade de Proteção Integral. Embora as terras ainda sejam de domínio privado, o órgão responsável deveria advertir a empresa pela obra e exigir uma medida de compensação ambiental, como exige a Lei do SNUC (SNUC, 2002).

Na zona 1, devido à alta especulação imobiliária nos últimos anos, parte da vegetação da porção sul e à jusante do Riacho das Piabas está sendo desmatada com grande intensidade, cujo objetivo é o de "limpar" as terras e transformá-las em reservas de valor futuro, sendo inicialmente utilizadas para o cultivo e criação de gado. De acordo com um dos responsáveis pelo desmatamento, a área será loteada após a conclusão da estrada da Alça Leste, melhorando o acesso.

Dessa forma, compreende-se que a execução do projeto Alça Leste dentro dos limites da UC torna-se o principal conflito de uso e desencadeador de outros conflitos, sendo um ativo de ameaça ao meio ecológico e a futura implementação do Parque, pois não somente impacta momentaneamente sobre os recursos naturais e a população local, mas é um tipo de infraestrutura que vai possibilitar um intenso tráfego de veículos, ocasionando perturbações a biota, além do povoamento de toda a região, atraindo empreendimentos do ramo imobiliário e especulando o preço da terra e, consequentemente, descaracterizando a paisagem conservada há anos.

A expansão da agricultura na zona 1 é um fator de uso conflitante que tem contribuído cada vez mais no isolamento dos fragmentos de bosque arbóreos. Além disso, outro problema 
ocasionado pela agricultura é a retirada da vegetação das vertentes, favorecendo a erosão laminar do solo, a alteração na topografia local e o consequente aparecimento de sulcos sobre o solo, gerando uma maior instabilidade no meio, conforme apontado por Tricart (1977).

Assim, pode-se considerar que as unidades de paisagens localizadas na zona 1 são as mais ameaçadas em relação as da zona 2, devido à alta frequência das atividades humanas sobre os seus recursos naturais e por serem muito fragmentadas e isoladas. Por localizar-se mais próximo à área urbana, a zona 1 consequentemente é também a mais especulada para a construção civil.

\subsection{Proposta de ordenamento territorial}

Com base nos resultados obtidos da valoração de Prioridade de Conservação (PRICON) para as unidades de paisagem da UC PAREST PRJO, conforme por ser observado no mapa da figura 9, buscou-se através de uma visão integrada e representativa propor ordenamentos de uso para cada unidade de paisagem específica, sob o que rege a lei e normas do SNUC para UCs do tipo parque, assim como com base no que já vem sendo realizado nessas unidades por diversos grupos no local.

Apesar dos valores elevados para as unidades de paisagem com maior prioridade de conservação, em geral localizadas na Zona 2 da UC PAREST PRJO, por possuírem valores naturais e culturais importantes, cabe ressaltar uma preocupação diferenciada com as unidades de paisagem que obtiveram valores baixos em Interesses de Conservação (INCON) e que ficaram fora de avaliação em PRICON, tratando-se de paisagens muito pobres em diversidade e que sofrem influências diretas das atividades antrópicas, levando em consideração que a área se trata de uma UC do tipo UPI, localizada em um dos biomas mais ameaçados e com déficits de áreas protegidas.

Dessa forma, a presente proposta de zoneamento da área da UC se torna mais reflexiva quanto aos dados de valoração da paisagem, não priorizando uma unidade de paisagem em detrimento da outra, buscando formas de zoneamento que visem a conservação e preservação dos seus recursos naturais de forma racional.

A Lei Federal n 9.985 que institui o SNUC e o Decreto de regulamentação de $n^{\circ} 4.340 / 2002$, estabelece a não permissibilidade do uso direto dos recursos naturais em UCS do tipo parque, sendo necessário a desapropriação e regulamentação da terra para domínio público e a criação de um plano de manejo e normas de uso, de modo que se possam atingir seus objetivos de preservação da natureza e proteção a biodiversidade. 


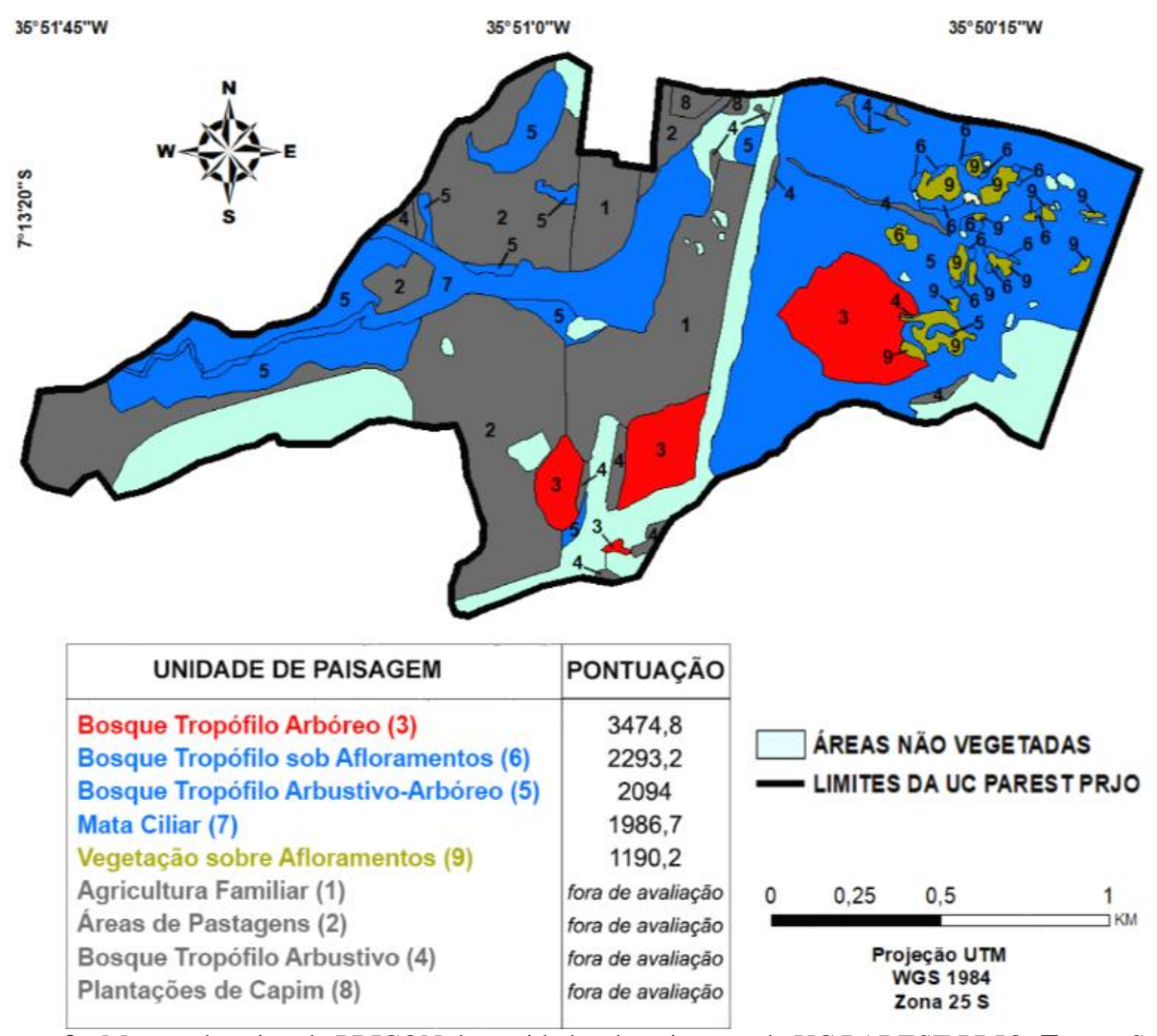

Figura 9 - Mapa valorativo de PRICON das unidades de paisagem da UC PAREST PRJO. Fonte: Souza (2017).

Assim, a regulamentação da situação fundiária torna-se imprescindível para que a UC PAREST PRJO possa atingir seus objetivos, sendo umas das intervenções mais importantes, cabendo ao Estado a regulamentação da área protegida. Além disso, cabe ao órgão gestor a responsabilidade de buscar formas de fiscalizar e conscientizar o uso dos recursos naturais da área.

Devido as condições ambientais e ameaças às unidades de paisagem da Zona 1, as intervenções indicadas dizem respeito a possibilidade de tentar recuperar a qualidade dos ecossistemas através da aplicação de técnicas que visem o reflorestamento da vegetação nativa. Além disso, essas áreas deveriam possuir um caráter mais conservacionista de uso, possibilitando experimentos científicos por se tratarem de ecossistemas degradados, mas que possuem indicadores ambientais e ecológicos interessantes para se compreender a dinâmica dos ecossistemas semiáridos localizados próximos a núcleos urbanos, contemplando assim alguns dos objetivos da UC.

A respeito da construção da Alça Leste, uma medida de compensação ambiental muito utilizada para mitigar o impacto da construção de estradas em UCs é a criação de Estradas-Parques, 
que é um tipo de intervenção de reflorestamento realizado nas adjacências da estrada para compensar o impacto do efeito visual da estrada e o efeito sonoro do fluxo de veículos sobre as paisagens circundantes, além de outras alternativas que visem a circulação de animais de um lado para outro da estrada, como a construção de túneis, corredores ecológicos e pontes.

A Zona 2 possui em sua maioria unidades de paisagem de elevada pontuação no parâmetro valorativo de interesse de conservação (INCON) e prioridade de conservação (PRICON), necessitando de um manejo que garanta a continuidade da regenerabilidade dos fragmentos e conservação das paisagens como um todo, por se tratar de um tapete vegetal continuo e mesclado com vários afloramentos rochosos, sendo a área da UC com maior geodiversidade.

O mapa de localização das áreas da UC necessárias para intervenções possibilita compreender espacialmente a proposta das indicações de uso para cada uma delas, conforme pode ser visualizado na figura 10.

\section{Proposta de intervenções e indicações de uso para a UC PAREST PRJO}

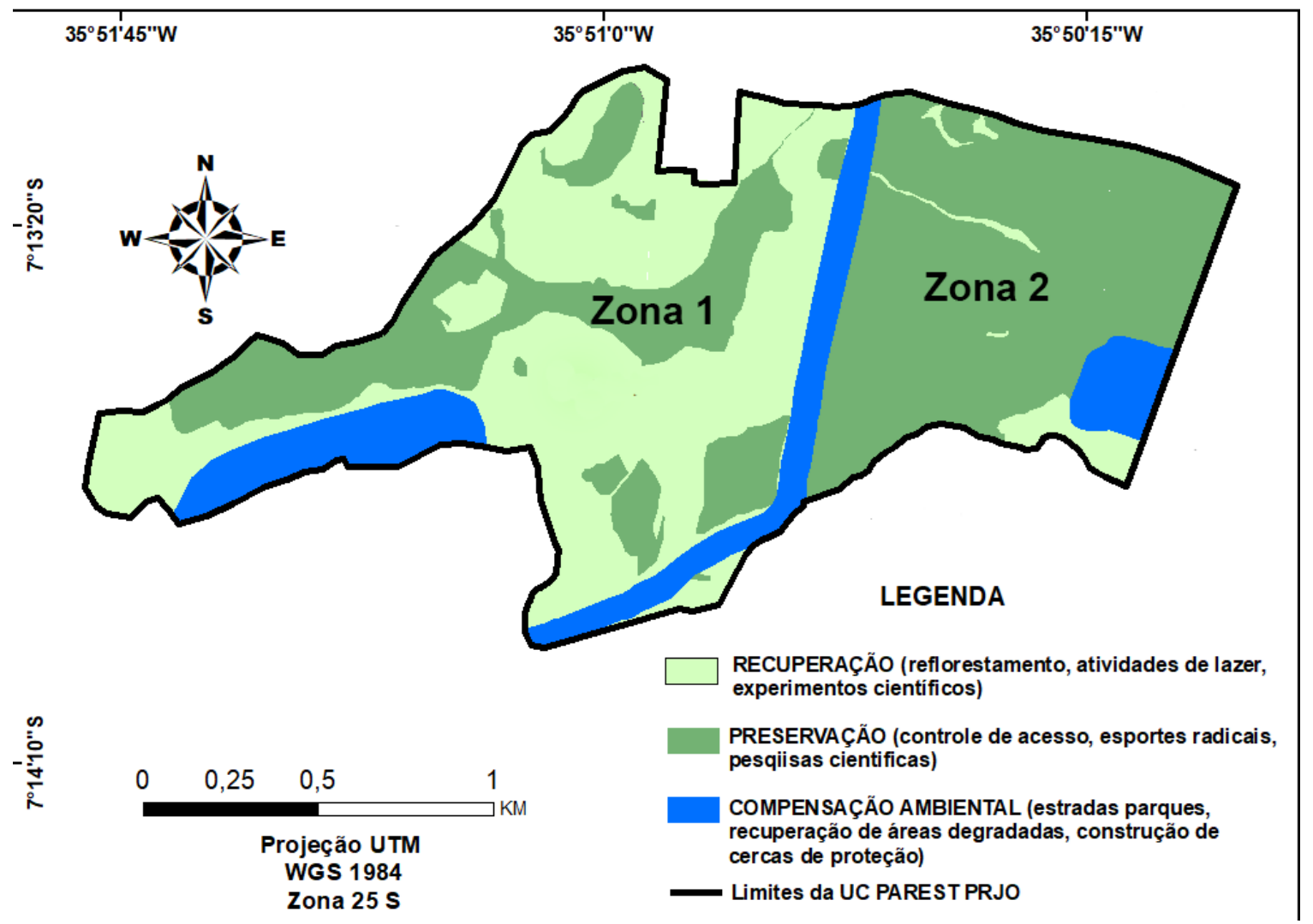

Figura 10 - Mapa das áreas para intervenção e indicações de uso na UC PAREST PRJO. Fonte: Souza (2017).

No mapa da figura 10, as áreas em azul correspondem aos principais usos conflitantes que causam ameaças muito preocupantes e impossibilitam a UC de ser implementada e atingir seus objetivos de proteção integral, como o condomínio horizontal, a obra de construção da Alça Leste e 
a exploração mineral de saibro e granito. Para essas atividades a proposta é de que hajam compensações ambientais pelos impactos causados a UC PAREST PRJO, destinando esses recursos para a aquisição de mecanismos de proteção da UC.

As áreas em verde claro na figura 10 também correspondem aos usos conflitantes que causam ameaças a UC e as unidades de paisagem que obtiveram pontuações muito baixas em INCONFOR, sendo indicado como intervenção um manejo de recuperação das áreas degradadas, com a aplicação de técnicas de reflorestamento. As destinações de uso para essas áreas são aquelas que envolvem experimentos e pesquisas científicas, atividades de lazer/visitação, construção de benfeitorias e infraestruturas para o funcionamento da UC, desde que permita recuperar a área.

Já as áreas em verde escuro correspondem as unidades de paisagem que obtiveram maiores pontuações em PRICON, sendo indicado para essas áreas intervenções que visem uma preservação maior dos ecossistemas, principalmente aos que se localizam na Zona 1, pois são muito fragmentados, pequenos e ameaçados, e requerem uma atenção especial de manejo.

Os usos para essas áreas devem ser controlados de forma que os impactos sobre os ecossistemas sejam minimizados, como por exemplo a prática de esportes radicais que já vem sendo realizados há anos por diversos grupos na Zona 2 e que não trazem prejuízos aos recursos naturais, porém desde que manejadas de forma correta, como a escalada em rocha, trilhas ecológicas de bicicleta e a pé, camping, rappel etc. Além disso, usos educativos e de turismo também podem ser explorados, utilizando-se dos caminhos e estradas presentes no interior dos fragmentos e nas adjacências da UC, bem como da topografia irregular em que se encontram os afloramentos rochosos, fomentando uma conscientização sobre a preservação e conservação da natureza.

Pesquisas científicas também são indicadas para essas áreas, porém de forma controlada e respeitando a Lei.

Uma gestão participativa e eficaz desses recursos naturas trariam muitos benefícios para a comunidade local e para o município de Campina Grande e demais municípios vizinhos, tais como o aproveitamento de serviços ambientais essenciais para a vida humana, como o melhoramento do clima local, conservação dos solos e da vegetação nativa, proteção a biodiversidade da fauna e flora, ciclagem da água, local de lazer, maior produtividade agrícola aos estabelecimentos localizados nos arredores etc., conforme aponta Constanza et. al., (1997), além de trazer novas perspectivas de conscientização e educação ambiental e melhor aproveitamento dos recursos naturais sob um viés sustentável. 


\section{CONSIDERAÇÕES}

Considera-se que valoração da paisagem se mostra como um importante método para o ordenamento territorial e gestão dos recursos naturais, pois engloba uma série de perspectivas científicas sobre a paisagem, desde a valoração num sentindo ecológico à identificação de ameaças aos recursos naturais.

Constatou-se diversos usos conflitantes na UC PAREST PRJO que ameaçam os seus recursos naturais e dificultam a regularização como UC de proteção integral, devido à falta de gestão e fiscalização do órgão gestor.

Pode-se admitir que a forma da criação da UC PAREST PRJO reflete um processo errôneo do poder público em todas as suas esferas, erro este tão comum na história da criação de áreas protegidas no país, que é o ato de criar UCs sem planejamento, ou seja, apenas por decreto, o que acaba interferindo na sua plena implementação futura devido aos vários problemas que se desencadeiam ao longo do tempo, como a descaracterização da paisagem, sendo um paradoxo face a uma legislação ambiental tão bem estruturada, a exemplo da lei do SNUC.

Considera-se até o momento que a problemática que envolve a sua regularização trata-se eminentemente de uma questão política, de interesses divergentes quanto a preservação e conservação dos recursos naturais presentes na área, em detrimento do seu aproveitamento para fins de especulação imobiliária e expansão da malha urbana para atender a iniciativa privada com a construção de condomínios dentro da área que deveria ser de proteção ambiental, como duas forças econômicas que não interagem com os anseios da civilidade consciente do século XXI.

A UC PAREST PRJO possui importantes valores do ponto de vista conservacionista, tornando-se urgente a necessidade de trazer tais questões para a sociedade na busca por soluções tangíveis e medidas conservacionistas para reverter o quadro de degradação no local.

\section{REFERÊNCIAS:}

AESA. Agência Executiva de Gestão de Águas do Estado da Paraíba. Governo do Estado da Paraíba. Secretaria de Estado da Ciência e Tecnologia e do Meio Ambiente. PERH-PB: Plano Estadual de Recursos Hídricos: Resumo Executivo \& Atlas. Brasília, DF, 2006. $112 p$.

ALMEIDA, C. N. et. al. Sm-Nd isotopes geochemistry and U/Pb geochronological data of the Campina Grande Complex, Paraíba State, NE Brazil. In: SIMPÓSIO DE GEOLOGIA DO NORDESTE, 17. Boletim 15. Fortaleza, SBG/NE, Fortaleza, 1997. 6-9. 
BRASIL. Lei Federal no. 9.985, de 18 de julho de 2000 (Institui o Sistema Nacional de Unidades de Conservação da Natureza - SNUC).

, Ministério do Meio Ambiente- MMA: Bioma Caatinga. Disponível em:

<www.mma.gov.br/biomas/caatinga>. Acesso: janeiro de 2017.

SNUC- Sistema Nacional de Unidades de conservação: texto da Lei 9.985 de 18 de julho de 2000. São Paulo - SP: Conselho Nacional da Reserva da Biosfera da Mata Atlântica, 2004. $76 \mathrm{p}$.

. Unidades de Conservação. Disponível em: < http://www.mma.gov.br/areas-

protegidas/unidades-de-conservacao>. Acesso: novembro de 2016.

CÁMARA, R. Escalonamiento Bioclimático, Regímenes Ecodinámicos y Formaciones Vegetales de la Isla de la Española en República Dominicana. Estudios em Biogeografía. Girona (ESP): Terrassa/Servei de Publications de la Universitat de Girona. 2004. p. 39-58,

CÁMARA, R. República Dominicana: dinámica del medio físico en la regióndel Caribe. Aportación al conocimiento de la tropicalidad insular. Tese de doutorado. Sevilla. Universidad de Sevilla, 1997. 1000 p.

CONSTANZA, R. et. al.The value of the world's ecosystem services and natural capital. Journal Nature, n³87, 1997, p. 253-260.

DIOS, C. B. de; MARÇAL, M. dos S. Legislação Ambiental e a Gestão de Unidades de Conservação: o caso do Parque Nacional da Restinga de Jurubatiba - RJ. In: GUERRA, A. J. T.; COELHO, M. C. N. (orgs). Unidades de Conservação: abordagens e características geográficas. Rio de Janeiro: Bertrand Brasil, 2009, p. 173-199.

FEITOSA, M. J. da S.; CÂNDIDO, G. A.; FIRMO, L. A. Sistemas de Indicadores de Sustentabilidade: uma aplicação do Ecological Footprint Method no município de Campina Grande (PB). Rev. Ambiência. v.6 n.3 p. 393 - 414, 2010. Disponível em: < revistas.unicentro.br/index.php/ambiencia/article/download/960/1141> Acesso: 05 de Julho de 2016.

FELICIANO, M. L. M.; MELO, R. B. Atlas do Estado da Paraíba: informações para gestão do patrimônio natural. João Pessoa: SEPLAN/IDEME/APAN/UFPB, 2003.

JÚNIOR, E. de C.; COUTINHO, B. H.; FREITAS, L. E. de. Gestão da Biodiversidade e Áreas Protegidas. In: GUERRA, A. J. T.; COELHO, M. C. N. (Org.). Unidades de Conservação: abordagens e características geográficas. Rio de Janeiro: Bertrand Brasil, 2009, p. 25-65.

PÁDUA, M.T.J. Unidades de conservação: muito mais do que atos de criação e planos de manejo. In: Unidades de Conservação: Atualidades e Tendências, MILANO, M. S. (org.) — Curitiba: Fundação O Boticário de Proteção à Natureza, 2002. 
SOUZA, A. S. Consequências da expansão imobiliária sobre a Unidade de Conservação Ambiental Parque Estadual do Poeta e Repentista Juvenal de Oliveira, Campina Grande, PB. Trabalho de Conclusão de Curso (Graduação em Geografia) - Monografia- Universidade Estadual da Paraíba, Centro de Educação, 2012. 84 f.

A. S. Valoração da Paisagem da Unidade de Conservação Parque Estadual do Poeta e Repentista Juvenal de Oliveira - Campina Grande - PB: proposta de ordenamento territorial. Dissertação de Mestrado apresentada ao Programa de Pós-Graduação em Geografia da Universidade Federal da Paraíba, 2017, 256 p. (no prelo).

TRICART, J. Ecodinâmica. SUPREN/IBGE, Rio de Janeiro, 1977.

VALLEJO, L. R. Unidades de conservação: uma discussão teórica à luz dos conceitos de território e de políticas públicas. Revista Geographia (Niterói), v.4, n.8, p.51-72, 2002. Disponível em http://www.uff.br/geographia/ojs/index.php/geographia/article/viewArticle/88 Acessado em 20 de julho de 2015.

VALENCIA, P. J. L et. al. Metodología de inventariación y Valoración de los paisajes vegetales. Revista Okara: Geografia em debate, v. 9, n. 2, p. 325-361, 2015b. ISSN: 1982-3878, João Pessoa, PB.

Recebido em: 15/08/2018

Aceite para publicação em: 05/11/2018 